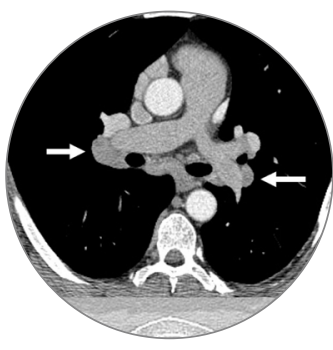

Palabras clave (DeCS)
Tomografía
computarizada
multidetector
Enfermedades
pulmonares
intersticiales
Enfermedades del tejido
conjuntivo
Enfermedades de la piel
Key words (MeSH)
Multidetector computed
tomography
Lung diseases, interstitial
Connective tissue
diseases
Skin diseases

Médico, Departamento de Radiología, Hospital Universitario San Ignacio, Pontificia Universidad Javeriana, Country Scan Ltda. Bogotá, Colombia. ORCID: https:// orcid.org/0000-0002-30932509

2Médico, Pontificia Universidad Javeriana. Bogotá, Colombia. ORCID: https://orcid. org/0000-0002-0347-3263

\title{
Manifestaciones torácicas y dermatológicas de las enfermedades sistémicas: claves para el radiólogo general
}

\author{
Thoracic and Cutaneous Involvement in Systemic Diseases: Clues for \\ the General Radiologist
}

Felipe Aluja-Jaramillo Jairo Mahecha

\begin{abstract}
Resumen
Hay una gran cantidad de enfermedades con manifestaciones en tórax y en piel. Dentro de ellas es muy importante la identificación de patrones radiológicos en tomografía computarizada multidetector (TCMD) y su correlación con la clínica, con énfasis en las manifestaciones cutáneas. En este artículo se hace una revisión de las principales entidades infecciosas, inflamatorias, enfermedades de tejido conjuntivo, enfermedades hereditarias y adquiridas. Se brinda información sobre las presentaciones radiológicas más frecuentes en el tórax, como la enfermedad intersticial pulmonar en la que predominan los patrones NINE, NIU y NO, cuya frecuencia varía según la enfermedad y que, a su vez, son diferentes de los patrones radiológicos en TCMD. Se destaca su importancia en pacientes con patologías dermatológicas. Se plantean hallazgos dermatológicos y radiológicos claves para sospechar el diagnóstico de estas patologías, lo que permite al radiólogo entregar una mayor información para definir el tratamiento y seguimiento de dichos pacientes.
\end{abstract}

\section{Summary}

There are many diseases with manifestations in the chest and on the skin. Within this great variety of diseases, it is important the identification of pathological patterns in Multidetector Computed Tomography (MDCT) and its correlation with cutaneous manifestations. In this article, we present a review of the main entities: infectious, inflammatory, connective tissue diseases, hereditary and acquired diseases. Information is provided on the most frequent radiological presentations of these diseases in the thorax, being one of the most frequent presentations the pulmonary interstitial disease where NSIP, UIP, and NO are the predominant patterns, whose frequency varies according to the disease and which, in turn, are different from the radiological patterns in MDCT. The importance of the Multidetector Computed Tomography in patients with dermatological pathologies is highlighted. Key dermatologic and radiologic findings to suspect the diagnosis in any of these pathologies are presented, which allows the radiologist to provide more information to define the treatment and follow-up of these patients.

\section{Introducción}

Un número considerable de patologías afectan concomitantemente la piel y el pulmón, con distintos tipos de manifestaciones radiológicas por cada entidad tanto en su temporalidad como en las características imaginológicas que se abordarán individualmente en cada sección. Dentro de esta variedad de entidades se pueden encontrar de etiología infecciosa (endocarditis infecciosa y síndrome SAPHO), enfermedad inflamatoria (sarcoidosis), enfermedad del tejido conjuntivo (polimiositis y dermatomiositis, esclerosis sistémica, síndrome de Sjögren, lupus eritematoso sistémico y artritis reumatoide), hereditarias (neurofibromatosis tipo 1) y adquiridas (sarcoma de Kaposi).

El objetivo de este artículo es ofrecer al radiólogo general las herramientas para identificar patrones pa- tológicos en la tomografía de tórax de alta resolución (TACAR) o en la tomografía computarizada multidetector con medio de contraste de tórax (TCMD) y su correlación con las manifestaciones cutáneas de distintas entidades sistémicas que afectan la piel y el tórax simultáneamente, así como realizar una revisión de las principales entidades de cada grupo de patologías que generan manifestaciones tanto cutáneas como pulmonares, con énfasis en aquellas que se encuentran frecuentemente en la práctica radiológica diaria.

\section{Patrones radiológicos asociados a las enfermedades dermatológicas}

Es necesario realizar una breve introducción en algunos conceptos, que son importantes para la comprensión 
del compromiso torácico de las enfermedades dermatológicas. Las manifestaciones torácicas de las enfermedades dermatológicas son variadas; sin embargo, las más frecuentes son: hipertensión arterial pulmonar y enfermedad pulmonar intersticial (EPI) (1). La EPI ocurre principalmente en adultos mayores y está definida por el patrón radiológico presente en la TCMD y la histopatología del tejido, diagnóstico que puede o no, estar acompañado de síntomas y signos; la presentación clínica más frecuente es con disnea, tos crónica y estertores bibasales, clínica que no se correlaciona con síntomas constitucionales que sugieran enfermedad multisistémica (2). Dentro de los distintos patrones radiológicos que forman la EPI se deben considerar la neumonía intersticial no específica (NINE), neumonía intersticial usual (NIU), neumonía de organización (NO) y neumonía intersticial linfoide (NIL) (1). En las enfermedades dermatológicas predominan los patrones de NINE, NIU y NO (2-8); no obstante, se deben considerar otras causas - farmacológicas, exposicionales o factores de riesgo asociados a EPI, como el tabaquismo, reflujo gastroesofágico, infecciones virales (Epstein Barr y hepatitis C) y antecedentes familiares de EPI (2) -

Dentro del compromiso pulmonar de las enfermedades dermatológicas, la NINE es el patrón más frecuente de EPI y se presenta especialmente en la esclerosis sistémica y en la polimiositis/dermatomiositis (1). Este patrón se presenta con áreas de alteración de la arquitectura pulmonar: reticulación y predominio de áreas en "vidrio esmerilado", compromiso homogéneo en ambos pulmones, bronquiectasias por tracción en lóbulos inferiores, y con un característico respeto del espacio subpleural (1). La NINE tiene una fase celular, en la que se inicia el compromiso pulmonar, y una fase fibrótica, en la que los hallazgos son más graves, con formación de "panal de abejas", algunas veces imposible de diferenciar del patrón de NIU (1). El patrón en "panal de abejas" se refiere a espacios aéreos quísticos de 3 a $10 \mathrm{~mm}$ de diámetro, con paredes gruesas y bien definidas, acompañadas de opacidades reticulares con bronquiectasias de tracción y bronquioloectasias (2). Da la apariencia de panal por las múltiples capas de quistes subpleurales que se ubican una sobre otra; sin embargo, en algunos casos puede ser solo una capa, lo que dificulta el diagnóstico diferencial con enfisema paraseptal o bronquiectasias de tracción (2) (figura 1).

La NIU es el segundo patrón más frecuente en entidades dermatológicas, predomina en pacientes con afección pulmonar por artritis reumatoide (1). Este patrón se caracteriza por alteración de la arquitectura pulmonar, escasas opacidades en "vidrio esmerilado", opacidades reticulares, bronquiectasias de tracción y formación de "panal de abejas" de predominio en lóbulos inferiores, con una característica de heterogeneidad temporal $(1,2)$ (figura 2). Se debe esclarecer la diferencia entre el patrón típico de "vidrio esmerilado" de la NIU —el cual consiste en opacidades superpuestas a un patrón reticular - y una opacidad en "vidrio esmerilado puro" —que sería indicativo de una exacerbación aguda en un paciente con EPI- y es más sugestivo de exacerbación si se acompaña de "vidrio esmerilado" bilateral con o sin consolidación y fibrosis pulmonar en segundo plano (2). Las guías más recientes (2) recomiendan clasificar la EPI en cuatro categorías según los hallazgos en TCMD:

- Patrón de NIU: Se observa "panal de abejas", que puede o no estar acompañado de bronquiectasias y bronquioloectasias. La típica distribución suele ser subpleural con predominio basal, usualmente heterogénea.

- Patrón probable de NIU: Se evidenciarían opacidades reticulares subpleurales, de predominio basal y heterogéneo. Puede estar acompañado de opacidades en "vidrio esmerilado", bronquiectasias y bronquioloectasias.

- Patrón indeterminado de NIU: Se caracteriza por tener patrón de fibrosis pulmonar, sin que concuerde con un patrón de NIU y tampoco con un patrón probable de NIU. Otras alternativas diagnósticas: Plantear diagnósticos alternativos según los hallazgos predominantes.

La neumonía de organización (NO) es poco frecuente como manifestación torácica; sin embargo, se ha descrito en pacientes con polimiositis/dermatomiositis (1). Se caracteriza por áreas de consolidación de distribución periférica o peribronquial de predominio en lóbulos inferiores y consolidaciones en forma poligonal o geográfica, que pueden estar rodeadas por áreas de "vidrio esmerilado", denominado signo del "halo reverso" (1). Es importante su diagnóstico ya que la NO se caracteriza por una buena respuesta al manejo con corticosteroides (1).

\section{Etiología infecciosa}

\subsection{Endocarditis bacteriana}

La endocarditis bacteriana se define como la infección del revestimiento interno de las válvulas y cavidades cardiacas (9). El microorganismo causal más común es el Staphylococcus aureus (10). Se han descrito condiciones predisponentes, como estenosis aórtica calcificada, enfermedad cardiaca congénita, episodios previos de endocarditis, válvulas protésicas —-más comúnmente en la mitral—, catéteres venosos centrales infectados, enfermedad periodontal, o en paciente usuarios de drogas endovenosas $(9,11)$.

Las manifestaciones dermatológicas son muy sugestivas para su diagnóstico; sin embargo, suelen ser poco comunes, con una prevalencia de, aproximadamente, un 11,9\%, según lo reseña la literatura (12). El embolismo periférico es el síntoma que afecta con mayor frecuencia las extremidades, en especial los dedos de las manos o de los pies (9). Los nódulos de Osler, lesiones de Janeway y hemorragia subungueal, que se caracteriza por ser lineal o en "astilla", son otros hallazgos de este tipo de entidades $(9,12)$.

Ahora bien, el abordaje diagnóstico se suele iniciar con un ecocardiograma para aclarar el diagnóstico, o sospecharlo, por el hallazgo de vegetaciones en válvulas cardiacas (13). Hay otras modalidades de imagen, como la radiografía de tórax, TACAR o TCMD y la resonancia magnética (RM), en las que se pueden identificar hallazgos útiles para el diagnóstico. En radiografía de tórax, TACAR y TCMD es característica la aparición de múltiples nódulos pulmonares, sólidos, de márgenes mal definidos, con predominio periférico, que pueden cavitar de acuerdo con el tiempo de evolución de la enfermedad y con una mayor profusión hacia la región subpleural o basal (9) (figura 3). Estos nódulos tienen un signo denominado "vaso nutricio", que consiste en un vaso que se dirige directamente al nódulo, hallazgo que se ha descrito hasta en el $100 \%$ de pacientes con embolismo séptico (11). En estos casos, el vaso no siempre corresponde a circulación arterial pulmonar, también puede corresponder a venas pulmonares (11). También se han descrito opacidades subpleurales en forma de cuña (11).

\subsection{Sindrome SAPHO}

El acrónimo SAPHO hace referencia a la descripción que le dieron Chamot y colaboradores en 1987 a la relación entre lesiones musculoes- 
queléticas, específicamente sinovitis, hiperostosis, osteítis y lesiones de piel: pustulosis y acné severo, descrito en francés como le syndrome acne-pustulose-hyperostose-osteite (14). El síndrome SAPHO se caracteriza por una exagerada reacción inmunológica a la infección bacteriana por el Propionibacterium acnés (15). Su prevalencia es igual en hombres y en mujeres, y debuta a una edad promedio de 30 a 55 años (16).

Sus síntomas clínicos son dolor inflamatorio localizado, edema de tejidos blandos y limitación para la movilidad, asociados a lesiones cutáneas que pueden ocurrir antes, durante o después de las manifestaciones óseas (16). En cuanto al compromiso cutáneo, se relaciona con pústulas amarillentas y vesículas, las cuales se limitan a las palmas y plantas (15). Además, brotes de acné — que pueden ser de características fulminans, conglobata o hidradenitis supurativa- que pueden acompañarse de nódulos ulcerosos y placas con costras, y usualmente ocurren en cara, espalda y pecho (15).

Los hallazgos radiológicos varían según la etapa de la lesión, tienen compromiso osteolítico en etapas tempranas de la enfermedad y osteoproliferativo en etapas tardías (14). En relación con la hiperostosis y la osteítis, se caracterizan por un incremento en la esclerosis del hueso (14). La hiperostosis se manifiesta con engrosamiento cortical y perióstico, mientras que la osteítis, con cambios trabeculares (15). El compromiso óseo predomina en huesos largos —en la metáfisis - en niños y en adolescentes; en adultos, en la pared anterior del tórax, particularmente en las uniones esternoclavicular y esternocostal (14). Es importante aclarar que las manifestaciones pueden estar en un único hueso, en el $67 \%$ de los pacientes, y en el restante, en múltiples huesos (de 2 a 6 huesos) (14).

El compromiso de la pared anterior del tórax es el más frecuente en esta entidad, y afecta entre el $60 \%$ y el $95 \%$ de los pacientes (14). Dentro de los hallazgos más comunes se evidencia entesopatía costoclavicular, focos hiperostóticos de alrededor de $5 \mathrm{~mm}$ de diámetro, usualmente localizados en el extremo proximal del esternón, adyacentes a la primera costilla, hallazgos que se consideran decisivos en el diagnóstico temprano de la enfermedad (15). La gammagrafía ósea ayuda en la detección de lesiones en pacientes asintomáticos, con captación del radiotrazador, especialmente en la región esternoclavicular, formando el signo característico, conocido en inglés como bull head sign (signo de "la cabeza del toro"), que ayuda esclarecer el diagnóstico de esta condición (15).

\section{Etiología inflamatoria}

\subsection{Sarcoidosis}

La sarcoidosis se considera como una enfermedad multisistémica, que consiste en un proceso inflamatorio crónico con una etiología no clara, cuya principal característica es la formación de granulomas no caseificantes en múltiples órganos; y el pulmón es el órgano más comúnmente afectado (9).

Entre el $20 \%$ y el $35 \%$ de los pacientes con diagnóstico de sarcoidosis van a presentar, en algún momento del curso de su enfermedad, manifestaciones cutáneas que pueden ser clasificadas en dos grupos: específicas y no específicas $(9,17)$. Las manifestaciones específicas más comunes son los nódulos maculopapulares, las placas y el lupus pernio, y se consideran especificas si en el examen histológico se evidencian granulomas no caseificantes (17). Entre las manifestaciones no específicas, la más relevante es el eritema nudoso (17). Incluso, se han descrito manifestaciones cutáneas que comprometen el aparato ungueal (18).
La sintomatología respiratoria de estos pacientes suele ser inespecífca, en su mayoría son asintomáticos. El estudio inicial es una radiografía de tórax, cuyos hallazgos pueden ser agrupados de acuerdo con la clasificación de Siltzbach $(9,19)$, que define cinco estadios de la sarcoidosis:

- Estadio 0: radiografía normal.

- Estadio 1: linfadenopatía.

- Estadio 2: linfadenopatía y enfermedad pulmonar.

- Estadio 3: afectación pulmonar.

- Estadio 4: fibrosis pulmonar (9).

La clasificación describe el rango de alteraciones que se encuentran en la radiografía en el momento del diagnóstico, que pueden ser desde una radiografía normal; demostrar únicamente adenomegalias mediastinales y parahiliares, en algunos casos calcificadas; mostrar únicamente hallazgos pulmonares como nódulos o masas; una combinación de nódulos pulmonares y adenomegalias mediastinales, hasta, en estadios finales, cambios de fibrosis pulmonar (9).

En la TCMD se van a observar adenomegalias mediastinales y parahiliares bilaterales que usualmente son simétricas (figura 4). Algunas de ellas pueden estar calcificadas con un patrón en "cáscara de huevo", y muestran realce homogéneo posterior a la administración del medio de contraste. En el parénquima pulmonar se encontrarán micronódulos de distribución perilinfática y subpleural (figura 4). Algunos de estos nódulos pueden confluir formando conglomerados o masas, además de masas o nódulos rodeados de otros nódulos de menor tamaño que configuran el denominado signo de la "galaxia", opacidades perihiliares y cambios de fibrosis pulmonar que predomina en los lóbulos superiores (figura 4) (20). Puede haber manifestaciones en la pleura — que se observan como placas pleurales y, menos frecuentemente, derrame pleural (21) - y en la tráquea — que se detectan como áreas de estenosis por compresión extrínseca secundaria a las adenomegalias mediastinales y áreas de engrosamiento nodular o liso de los bronquios que pueden llevar a una estenosis (22)-.

\section{Enfermedades del tejido conjuntivo}

\subsection{Polimiositis y dermatomiositis}

La polimiositis y la dermatomiositis pertenecen al grupo de las enfermedades de tejido conjuntivo. Se caracterizan por generar un proceso inflamatorio del músculo estriado esquelético, que deriva en el déficit de fuerza en los grupos musculares proximales, mialgias y elevación de la creatina-cinasa (CK) (23). Ahora bien, cuando hay compromiso muscular y de la piel, específicamente erupción cutánea, se denominaría dermatomiositis, con una de sus presentaciones más características: las pápulas de Gottron. Su etiología es poco conocida; sin embargo, se cree que la polimiositis tiene relación con antígenos musculares, que en la dermatomiositis generan daño de la microvasculatura a causa de una respuesta inmune, la cual lleva a hipoperfusión y presencia de células inflamatorias en la región perifascicular $(9,23)$.

La manifestación cutánea tiene un papel relevante en el diagnóstico de la dermatomiositis, que permite clasificarla en 7 grupos diferentes: patognomónicas, características, compatibles, poco comunes, raras, descritas recientemente y manifestaciones no específicas en piel (24). Dentro del grupo de las patognomónicas se encuentran el signo de Gottron y las pápulas de Gottron. 
El signo se refiere a máculas eritematosas, en algunos casos descamativas, de características lineales, que se disponen sobre las vainas de los tendones extensores de las extremidades, más marcado en las zonas dorsal y lateral de las manos. Las pápulas de Gottron se representan como lesiones en el dorso de los metacarpianos, articulaciones interfalángicas y en el contorno de las uñas, son planas, papulares y de color violáceo. Por último, se debe tener en cuenta el otro subgrupo más frecuente: las lesiones características, en las que se encuentra el rash heliotropo, el signo "del chal" o signo "de V", telangiectasias periungueales y placas atróficas y escamosas del cuero cabelludo (24).

En cuanto a las manifestaciones torácicas de estas dos entidades, se han descrito neumonías intersticiales, vasculitis, hipertensión pulmonar y atrofia de músculos torácicos. El hallazgo de mayor significado clínico es el compromiso intersticial, con un patrón de neumonía de organización (NO) que puede aparecer incluso antes de la afección cutánea $(9,25)$. El compromiso pulmonar intersticial lo causa el anticuerpo asociado a miositis y los anticuerpos contra enzimas aminoacil ARNt sintetasa, que se correlacionan con su presentación clínica y el riesgo de desarrollar una enfermedad intersticial pulmonar (25). Otro de los patrones descritos es la NINE, hasta en un 13,7 \% de pacientes (5). La NINE y la NO no son mutuamente excluyentes, por lo que un mismo paciente puede tener hallazgos radiológicos e histológicos de ambas entidades simultáneamente (9). Otros compromisos relacionados con estas dos entidades son aquellos secundarios al tratamiento, infección o falla respiratoria, como neumonía por inmunosupresión, neumonía por aspiración relacionada con atrofia de los músculos de la faringe, falla respiratoria por adelgazamiento de músculos intercostales y efectos tóxicos del tratamiento farmacológico, este último también puede derivar en un patrón de NO (9).

\subsection{Esclerosis sistémica}

La esclerosis sistémica, o esclerodermia, es una patología autoinmune, que se caracteriza por producir fibrosis, daño vascular e inflamación (1). Al inicio de la enfermedad solo el $1 \%$ de los pacientes tienen síntomas respiratorios; sin embargo, el $60 \%$ los desarrollan en el trascurso de la enfermedad (26). Esta entidad afecta predominantemente a mujeres, en una relación $3: 1$, con un pico de incidencia entre los 45 y 64 años (27).

Las manifestaciones cutáneas de esta enfermedad más reconocidas son engrosamiento cutáneo - que inicia en los dedos de las manos-, isquemias digitales por vasculopatía, compromiso facial — que lleva a facies inexpresivas - y telangiectasias en boca, manos y pared torácica (9). Dichas manifestaciones se pueden dividir en limitadas y difusas. Cuando son limitadas, solo afectan la zona distal de las extremidades y la cara - también llamada esclerosis sistémica limitada, cuya principal forma o manifestación clínica es el síndrome de CREST (por las iniciales en inglés de calcinosis, fenómeno de Raynaud, dismotilidad esofágica, esclerodactilia y telangiectasias) (27)-. Cuando las manifestaciones son difusas, se encuentra la esclerosis cutánea en el tronco y en la zona proximal de los miembros inferiores y esclerodactilia — también denominada esclerosis sistémica difusa-. Esta división de compromiso cutáneo también guarda relación con distintas asociaciones clínicas y distinta relación con autoanticuerpos séricos específicos $(9,28)$. Cabe resaltar que, así como existe esta división de compromiso cutáneo, también está el subtipo de la sine esclerodermia (ESse), que afecta al $5 \%$ de pacientes con esclerodermia y se basa en tener la clínica sugestiva: fenómeno de Raynaud, úlceras digitales, hipertensión pulmonar arterial y autoanticuerpos para esclerosis sistémica, sin compromiso de la piel (28).

Al evaluar el compromiso torácico en esta entidad se debe tener en cuenta que estos pacientes pueden desarrollar fibrosis pulmonar, entidad que guarda relación con la presencia de anticuerpos antitopoisomerasa I, la cual se encuentra en un 10 a $16 \%$ de la esclerosis sistémica difusa $(27,29)$. El patrón más común en esta clase de pacientes es el de NINE (9). Al informar los resultados de los estudios se debe intentar determinar el porcentaje de compromiso pulmonar, ya que uno mayor al $20 \%$ (considerado extenso) tiene una tasa de mortalidad mayor y un rápido deterioro de la función pulmonar (1).

Otro hallazgo en TCMD es la hipertensión pulmonar arterial, que puede estar relacionada con el compromiso pulmonar (grupo 3) o por la vasculopatía primaria (grupo 1) (figura 5); sin embargo, también se ha encontrado que guarda relación con la presencia de anticuerpos anti-centrómero (ACA) $(9,29)$. Una manifestación muy frecuente — descrita en aproximadamente el $97 \%$ de pacientes con esclerosis sistémica - es la dilatación esofágica, la cual puede predisponer a neumonitis por aspiración o bronquiolitis (figura 5) (1).

\subsection{Síndrome de Sjögren (SJ)}

El SJ es una enfermedad inflamatoria autoinmune relacionada con la infiltración de linfocitos T en distintos órganos, como pulmón, riñones y glándulas exocrinas (8). Los más comúnmente afectados son las glándulas exocrinas - lacrimales y salivares - , lo que inhibe la secreción glandular y, por ende, causa mucosas secas (8). Tiene una prevalencia del $3 \%$ en adultos, con predominio en mujeres en una relación 9:1 y tiende a ser más común en la cuarta y quinta décadas de la vida (30). Se puede dividir en SJ primario — se encuentra como única presentación clínica - y SJ secundario — relacionado con otra enfermedad autoinmune (8)-.

Los síntomas principales de esta entidad son la xeroftalmia (queratoconjuntivitis seca) y xerostomía (1). Otras manifestaciones, como epistaxis, costras nasales o perforación del tabique nasal se deben al compromiso del tracto respiratorio superior (27). Si se afecta la vía aérea inferior, se presenta con sintomatología crónica, como tos seca, disnea y bronquitis recurrente (30). En estos pacientes es relevante determinar la presencia de síntomas $\mathrm{B}$, ya que tienen más riesgo de desarrollar linfoma - usualmente linfoma no-Hodgkin de células B- (1).

La enfermedad pulmonar intersticial afecta al $25 \%$ de pacientes con SJ (7). Dicho compromiso es más común en pacientes con SJ primario, y se observa con patrones como NINE, NIU, NO y NIL, menos común con patrones de bronquiolitis o amiloidosis $(1,26)$. Antiguamente se sugería que la NIL era el patrón más característico; sin embargo, en estudios recientes se encontró que la NINE es el patrón prevalente $(7,8)$. En la TCMD, la NIL se describe como áreas de "vidrio esmerilado", engrosamiento de septos interlobulillares, nódulos y quistes de pared delgada (1) (figura 6). En la bronquiolitis folicular se evidencia formación de quistes secundarios a la infiltración de linfocitos en la pared bronquial que genera una dilatación bronquiolar secundaria y, de esta manera, la apariencia quística $(1,27)$. 

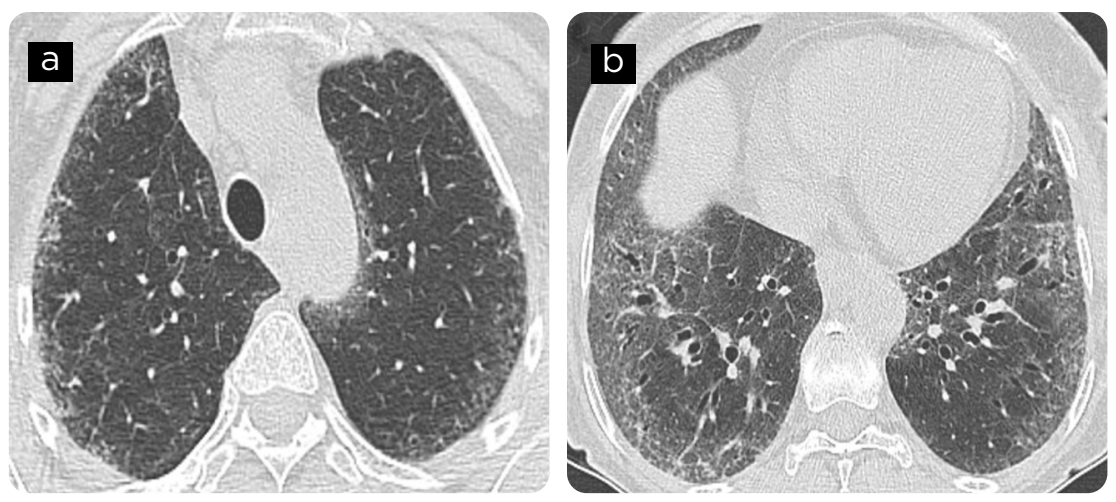

Figura 1. Paciente con diagnóstico de neumonía intersticial no específica (NINE). TC de tórax, ventana para pulmón. a) Corte axial en lóbulos superiores y b) en lóbulos inferiores. Alteración de la arquitectura pulmonar con opacidades en "vidrio esmerilado" asociado a reticulación y algunas bronquiectasias por tracción, sin formación de "panal de abejas"; configura un patrón indeterminado de neumonía intersticial usual en estudio histopatológico, que corresponde a neumonía intersticial no específica.
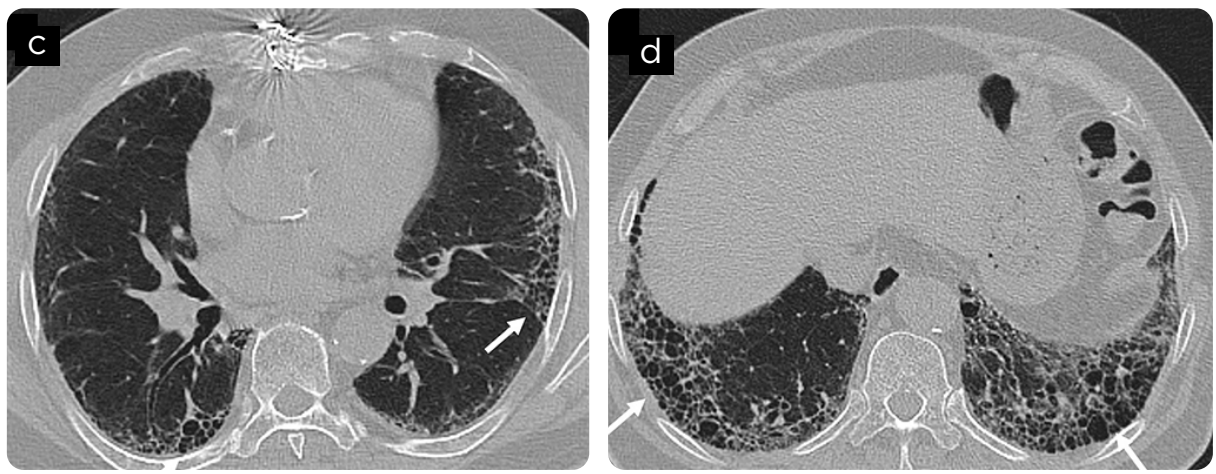

Figura 2. Paciente con diagnóstico de neumonía intersticial usual (NIU). TC de tórax, ventana para pulmón. a y b) Corte axial en lóbulos inferiores. Alteración de la arquitectura pulmonar con áreas de "panal de abejas" de predominio subpleural en lóbulos inferiores, asociado a engrosamiento irregular de septos interlobulillares y algunas bronquiectasias por tracción configurando patrón de neumonía intersticial usual.
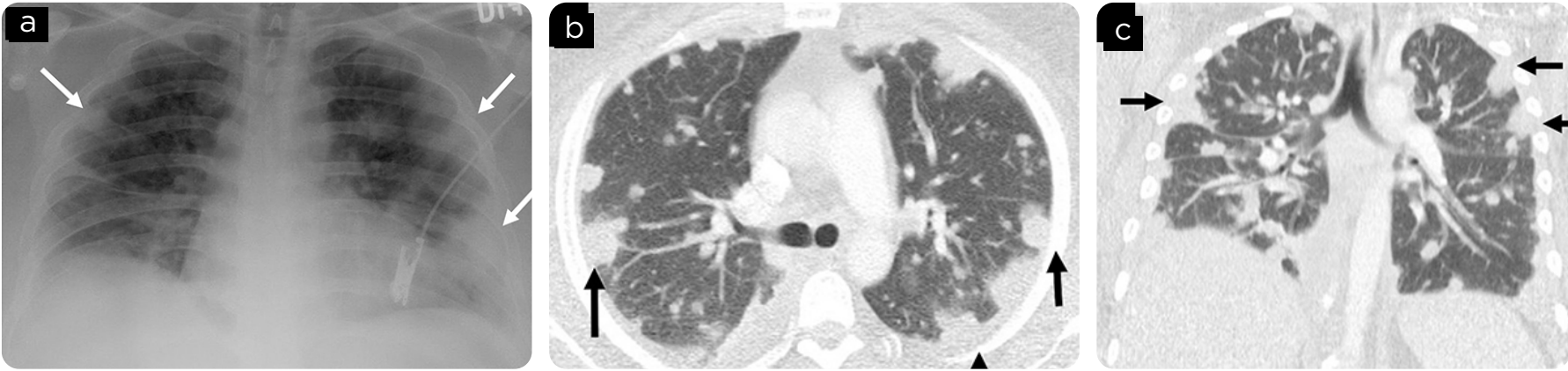

Figura 3. Paciente con diagnóstico de embolismo séptico. a) Rx de tórax proyección vanteroposterior. Múltiples nódulos con densidad de tejidos blandos en ambos pulmones, en su mayoría de predominio subpleural. TC de tórax, b) ventana para pulmón infracarinal y c) reconstrucción coronal. Múltiples nódulos sólidos de predominio subpleural en los diferentes segmentos pulmonares, algunos de ellos muestran áreas de cavitación central.
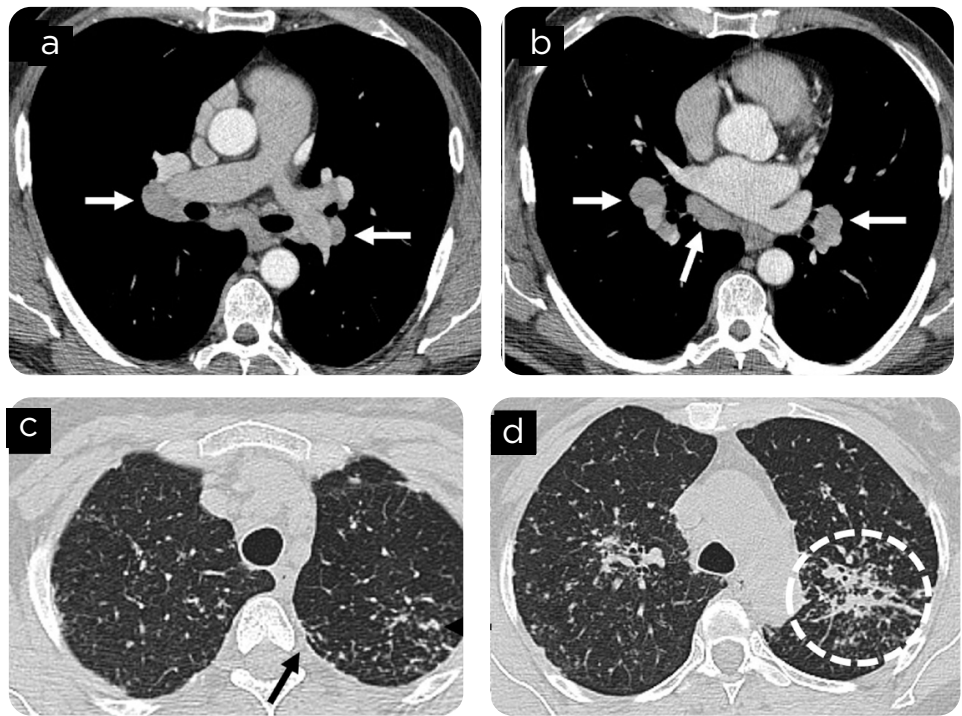

Figura 4. Paciente con diagnóstico conocido de sarcoidosis. TC de tórax con medio de contraste, ventana para mediastino. a) En la arteria pulmonar y b) en lóbulos inferiores. Múltiples adenomegalias mediastinales simétricas y bien definidas, con realce homogéneo posterior a la administración del medio de contraste que predominan en la región parahiliar (flechas) e infracarinales. c y d) TC simple de tórax, ventana para pulmón en lóbulos superiores. Se observan nódulos sólidos con densidad de tejidos blandos no mayores de 5 $\mathrm{mm}$, de disposición perilinfática (flechas), algunos de ellos confluyen formando "pseudomasas" y configurado el signo de "la galaxia" (línea punteada) 

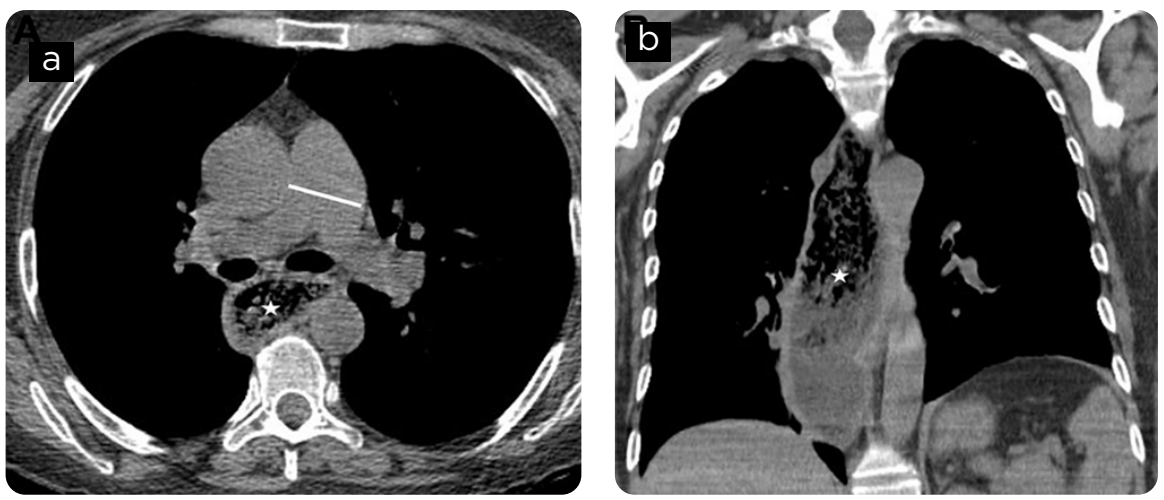

Figura 5. Paciente con antecedente de esclerosis sistémica. TC de tórax, ventana para mediastino. a) corte axial en lóbulos superiores y b) reconstrucción coronal. Prominencia de la arteria pulmonar principal por hipertensión pulmonar arterial (línea blanca en a). Hay dilatación del esófago en sus tres tercios (asterisco).
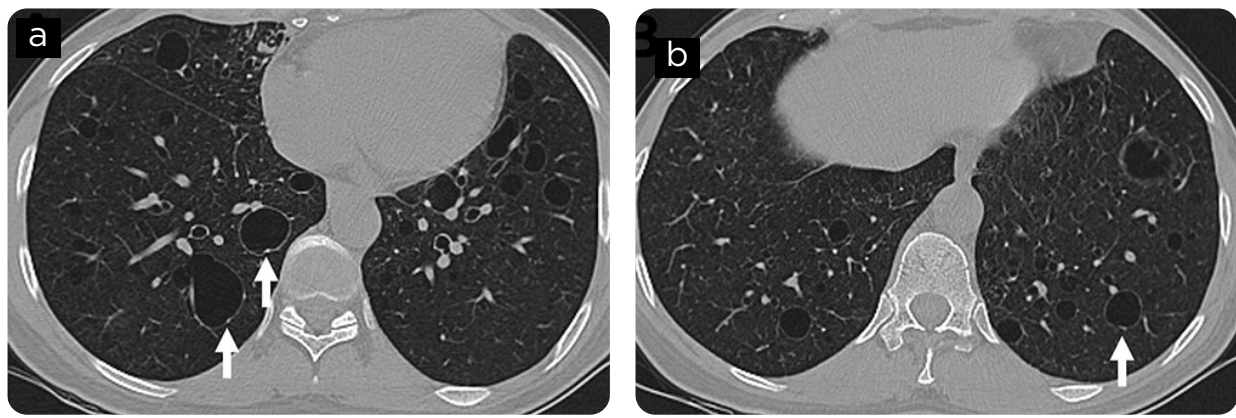

Figura 6. Dos pacientes con diagnóstico conocido de síndrome de Sjögren. a y b) TC ventana para pulmón, corte axial en lóbulos inferiores. Se aprecian imágenes de apariencia quística, de pared delgada, de predominio en lóbulos inferiores asociado a nodularidad de la pared de algunos quistes (flecha blanca) en relación a neumonía intersticial linfoide. c y d) TC de tórax, ventana para pulmón, c) corte axial en lóbulos inferiores d) y reconstrucción sagital. Bronquiectasias en lóbulos inferiores con engrosamiento de paredes bronquiales, especialmente en el lóbulo inferior izquierdo, en paciente con antecedente de síndrome de Sjögren.
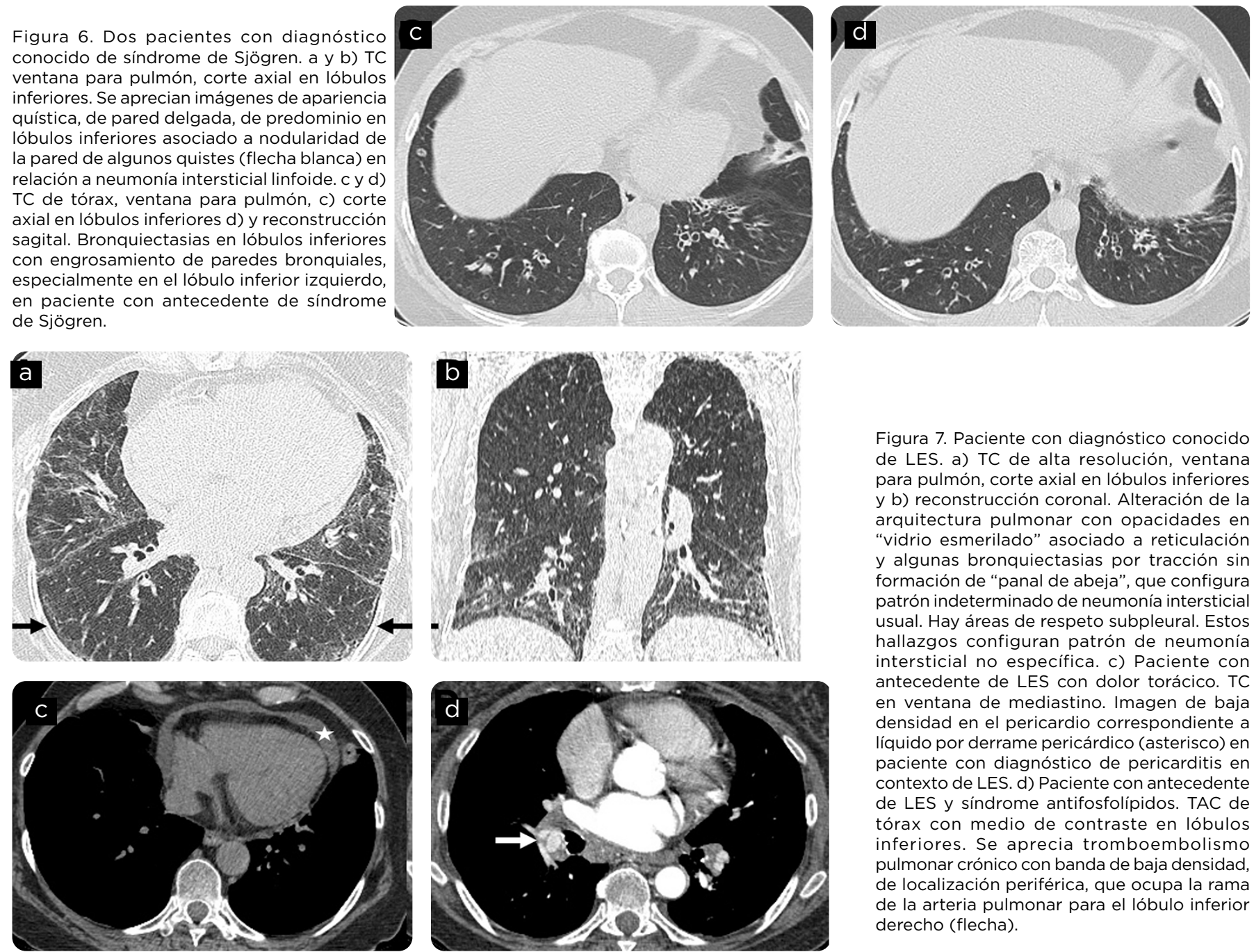

Figura 7. Paciente con diagnóstico conocido de LES. a) TC de alta resolución, ventana para pulmón, corte axial en lóbulos inferiores y b) reconstrucción coronal. Alteración de la arquitectura pulmonar con opacidades en "vidrio esmerilado" asociado a reticulación y algunas bronquiectasias por tracción sin formación de "panal de abeja", que configura patrón indeterminado de neumonía intersticia usual. Hay áreas de respeto subpleural. Estos hallazgos configuran patrón de neumonía intersticial no específica. c) Paciente con antecedente de LES con dolor torácico. TC en ventana de mediastino. Imagen de baja densidad en el pericardio correspondiente a líquido por derrame pericárdico (asterisco) en paciente con diagnóstico de pericarditis en contexto de LES. d) Paciente con antecedente de LES y síndrome antifosfolípidos. TAC de tórax con medio de contraste en lóbulos inferiores. Se aprecia tromboembolismo pulmonar crónico con banda de baja densidad de localización periférica, que ocupa la rama de la arteria pulmonar para el lóbulo inferior derecho (flecha). 

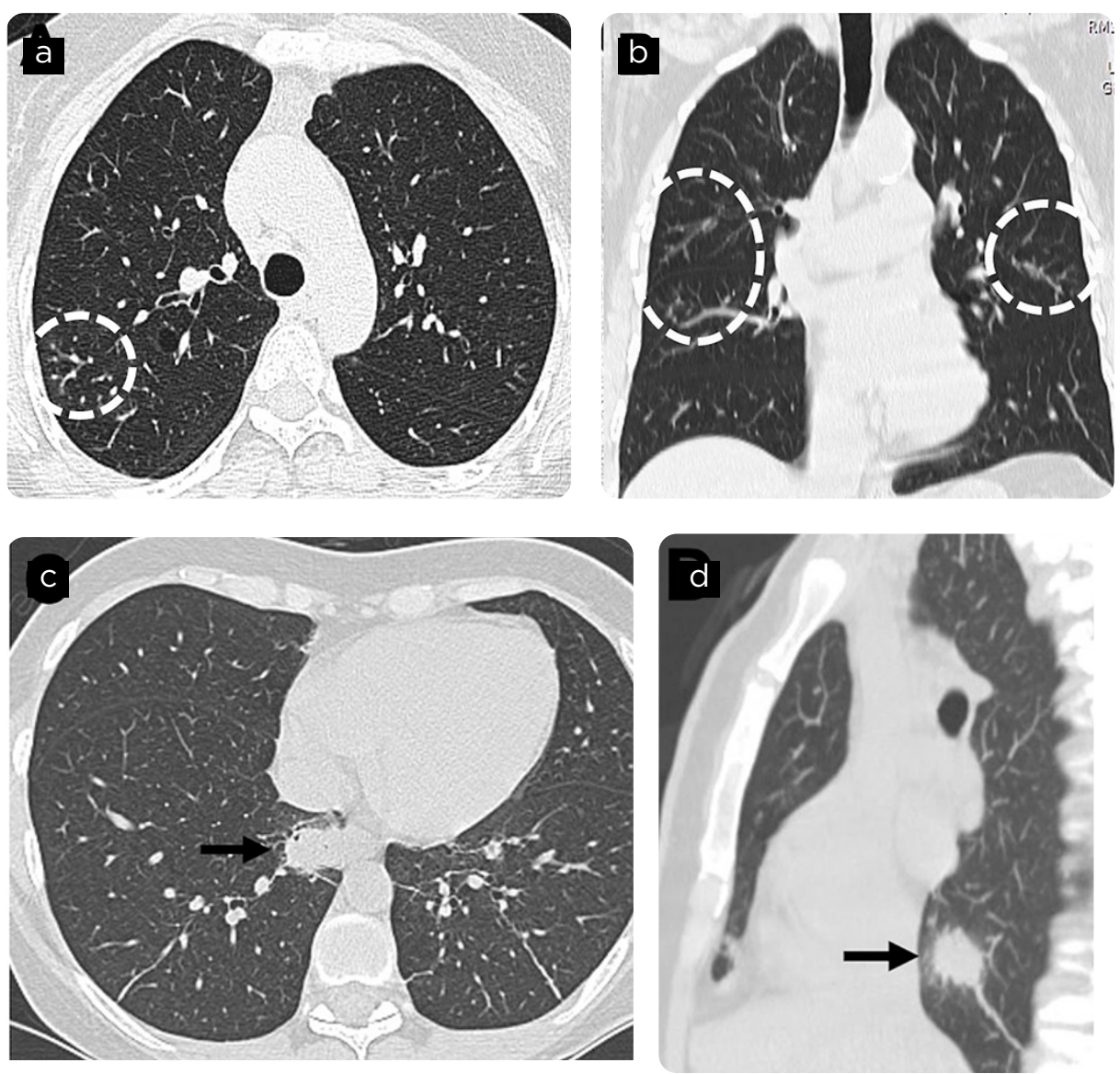

Figura 8. Dos pacientes con diagnóstico conocido de artritis reumatoide. TAC a) ventana para pulmón, corte axial y b) reconstrucción coronal. Se aprecian áreas de "árbol en gemación" (línea punteada) de carácter inespecífico, con informe histopatológico de bronquiolitis folicular en paciente con antecedente de artritis reumatoide. TAC de tórax, c) ventana para pulmón, corte axial en lóbulos inferiores y d) reconstrucción sagital. Se observa nódulo sólido, subpleural, ovalado, con densidad de tejidos blandos, de contornos parcialmente definidos con halo en "vidrio esmerilado" y pequeña zona central de baja densidad (en a) relacionado con nódulo reumatoideo que resolvió en controles posteriores.
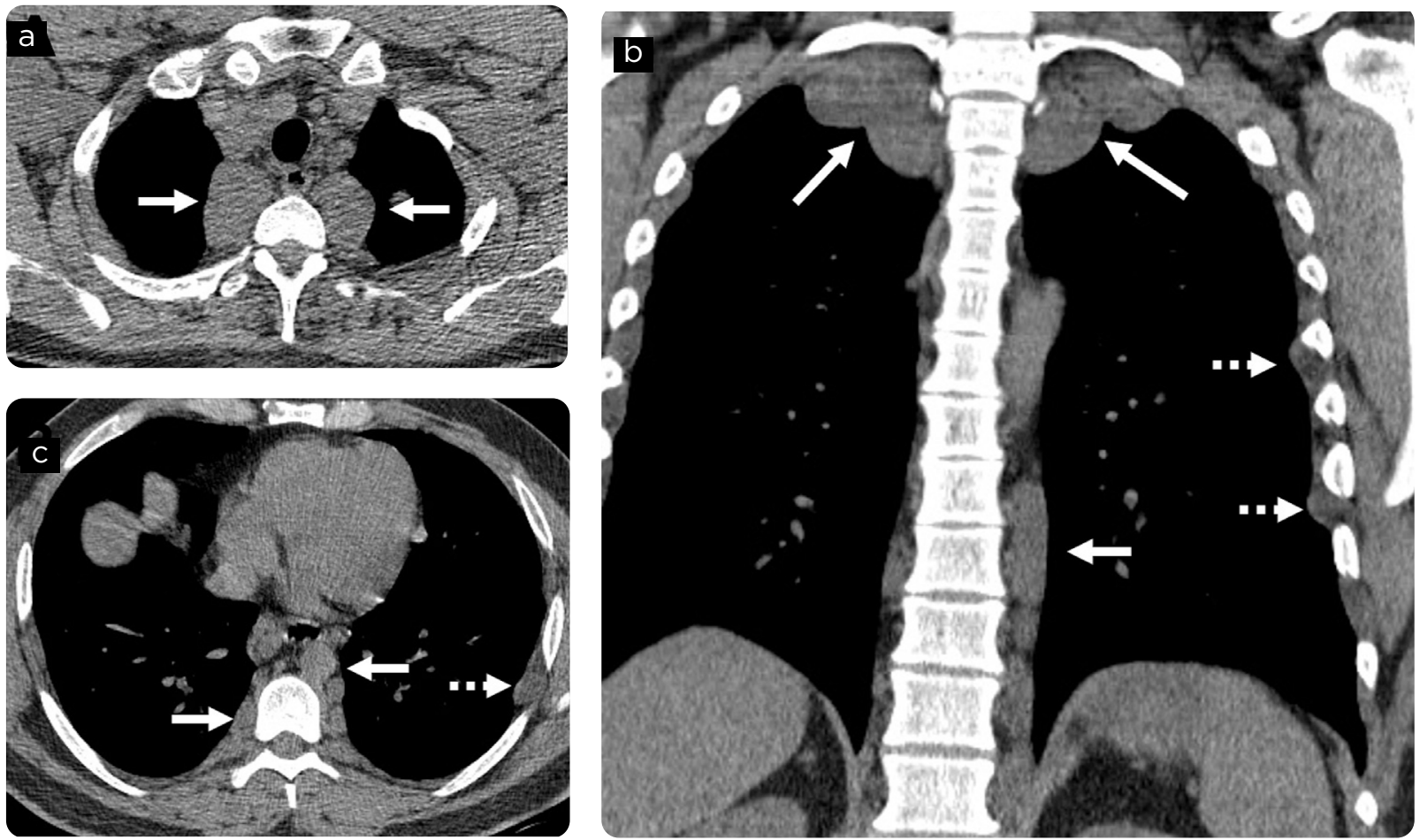

Figura 9. Paciente con antecedente de neurofibromatosis. TAC multidetector simple de tórax. a) Corte axial apical en los lóbulos superiores, b) corte axial caudal en los lóbulos superiores y c) reconstrucción coronal. Imágenes nodulares con densidad de tejidos blandos en el espacio mediastinal paravertebral (flechas blancas) y algunas en espacios intercostales (flecha punteada) correspondientes a neurofibromas. 

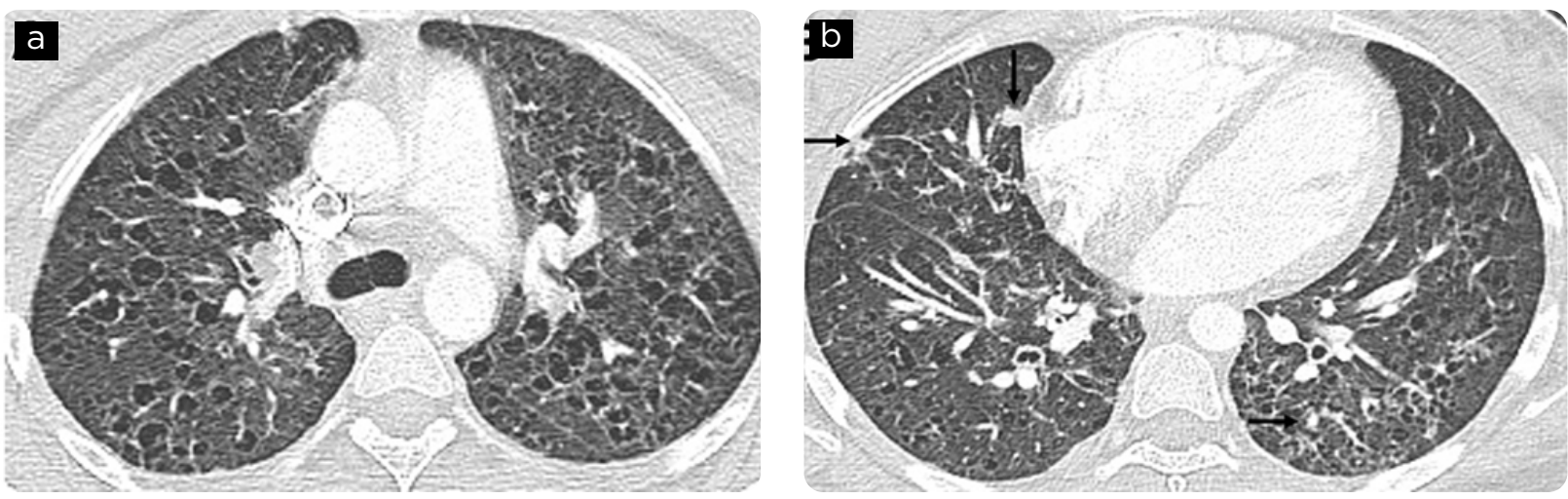

Figura 10. Paciente con esclerosis tuberosa y síntomas respiratorios progresivos. TAC de tórax, ventana para pulmón. a) Corte axial en lóbulos superiores, b) corte axial en lóbulos inferiores. Múltiples áreas de apariencia quística y pared delgada en los cuatro cuadrantes sugestivas de linfangioleiomiomatosis. Hay algunos pequeños nódulos de distribución aleatoria (flechas).
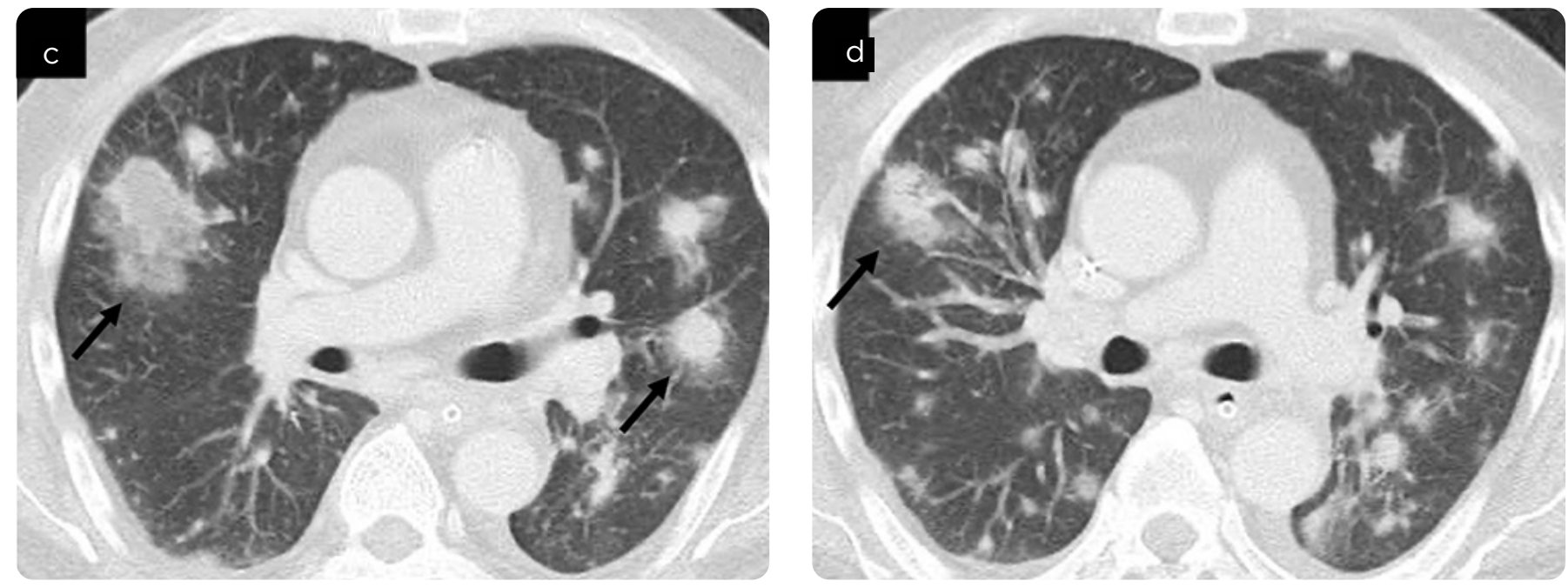

Figura 11. Paciente con antecedente de infección por virus de inmunodeficiencia humana. a y b) TAC, corte axial, en ventana de pulmón. Se observan algunas opacidades nodulares y masas de contornos parcialmente definidos con halo en "vidrio esmerilado" distribuidas en los diferentes segmentos pulmonares en paciente con diagnóstico conocido de sarcoma de Kaposi.

Otros hallazgos patológicos en la TCMD son las complicaciones de la vía aérea, con engrosamiento de paredes bronquiales, bronquiectasias, bronquioloectasias y áreas de atrapamiento aéreo (27) (figura 6). Es poco frecuente la afectación pleural o el derrame pleural; sin embargo, puede estar relacionado con otras enfermedades autoinmunes concomitantes, como AR o LES (30). Por último, si en la TCMD se observan consolidaciones, nódulos de gran tamaño y derrame pleural, se debe descartar el linfoma (27).

\subsection{Lupus eritematoso sistémico (LES)}

El LES es una enfermedad autoinmune multisistémica de tejido conjuntivo que afecta la piel, articulaciones, riñones y sistema nervioso central (9). Tiene una prevalencia de 20 a 70 por 100.000 personas al año (27). Esta entidad, que predomina en mujeres durante la edad reproductiva (90\%), tiene un pico de presentación entre los 15 y los 50 años (9). Las células apoptóticas se tornan antigénicas producto de la liberación de detritos celulares, lo que genera complejos inmunitarios y activación del complemento, con daño del tejido en el órgano afectado (9).
Entre los órganos más afectados están los riñones (nefritis lúpica) y la piel (31). El compromiso dermatológico ocurre en el $75 \%$ de los pacientes en el trascurso de la enfermedad, por lo que es importante su caracterización temprana, debido a que el $25 \%$ de los pacientes presentan alteraciones en la piel semanas o meses antes de tener síntomas sistémicos (31). Como manifestaciones del lupus eritematoso cutáneo se encuentran el eritema malar en "alas de mariposa", presentaciones subagudas con áreas de alopecia e hipopigmentación, manifestaciones recurrentes como pápulas y placas no cicatriciales relacionadas con exposición a rayos UV en cara, área cigomática y manos, además de otras variantes, como la anular con placas eritematosas en forma de anillo (31).

En cuanto al compromiso torácico, es importante precisar que la sintomatología respiratoria es nula o leve; no obstante, el dolor pleurítico es el principal síntoma, y guarda relación con el hallazgo imaginológico de derrame pleural bilateral y engrosamiento pleural, que se consideran manifestaciones de serositis (9). Estos hallazgos se han descrito en el $61 \%$ de los pacientes y como consecuencia, un pequeño porcentaje puede desarrollar fibrotórax, complicación en la que se evidencia un 
engrosamiento pleural liso, derrame pleural no libre o colecciones pleurales y atelectasias subyacentes $(27,32)$.

Las complicaciones infecciosas secundarias a las alteraciones (primarias o secundarias) del sistema inmune de estos pacientes pueden ser otras de las manifestaciones encontradas, especialmente aquellos en manejo con inmunomodulador (27). El hallazgo de neumonía adquirida en la comunidad es el más habitual; sin embargo, también se deben tener en cuenta los microorganismos atípicos, como micobacterias tuberculosas y no tuberculosas, Pneumocystis jirovecii, Citomegalovirus y Aspergillus (33).

El compromiso intersticial en LES es poco común, afecta entre el $3 \%$ y el $8 \%$ de los pacientes (34). El patrón más frecuente es la NINE $(1,27)$ (figura 7). La radiografía de tórax tiende a ser poco significativa, ya que en estadios leves a moderados los hallazgos suelen ser sutiles (32). La TACAR toma gran importancia, pues permite valorar las áreas de "vidrio esmerilado" en compromiso intersticial temprano (34).

Otras manifestaciones, como consolidaciones difusas, deben hacer pensar en entidades poco comunes, pero que ponen en riesgo la vida del paciente, como la hemorragia alveolar o la neumonitis, las cuales aparecen en menos del $2 \%$ y de $1,4 \%$ a $4 \%$ de los pacientes, respectivamente $(9,34)$. Otra entidad que se debe buscar, teniendo en cuenta la relación del LES con el síndrome antifosfolípidos es el tromboembolismo pulmonar (figura 7), el cual se debe descartar en paciente con clínica de disnea aguda con dolor pleurítico asociado (35). Ahora bien, existen manifestaciones muy poco frecuentes, como el "síndrome de pulmón encogido" (en inglés shrinking lung syndro$m e$ ), descrito en 1965 como una disminución progresiva de volumen pulmonar asociado a disnea y dolor pleurítico (36). Los hallazgos en radiografía de tórax y TCMD, como elevación unilateral o bilateral del diafragma, atelectasias basales y sin evidencia de compromiso parenquimatoso, dan la apariencia de pérdida de volumen o atelectasias $(36,37)$.

En el $58 \%$ a $77 \%$ de los casos hay manifestaciones cardiovasculares, el más frecuente es la pericarditis que debuta como derrame pericárdico (32) (figura 7). Otras afecciones cardiacas relacionadas con LES son: miocarditis, alteraciones valvulares - como la endocarditis de Libman-Sacks - y ateroesclerosis prematura de las arterias coronarias (32).

\subsection{Artritis reumatoide}

La artritis reumatoide (AR) es la enfermedad más común del tejido conjuntivo, afecta al $1 \%$ de la población mundial, en su mayoría a mujeres entre los 25 a 50 años (27). Es una poliartropatía inflamatoria, simétrica, que compromete las manos y pies; también puede causar afecciones en otros órganos (por ejemplo: pericarditis, esplenomegalia, inflamación ocular y nódulos subcutáneos) (38).

Se dan manifestaciones extraarticulares en un $40 \%$ de los pacientes diagnosticados con AR (39). Son más frecuentes en hombres y guardan relación con una mayor elevación de los títulos de factor reumatoide y anticuerpos antipéptido citrulinado cíclico (antiCCP) (40). El compromiso cutáneo es una de las formas más frecuentes, e incluye presentaciones clínicas como nódulos reumatoides, nodulosis reumatoides, síndrome Felty, vasculitis reumatoides, pioderma gangrenoso, entre otros, sin olvidar el compromiso cutáneo relacionado con tratamiento para la AR (41).
En los pacientes con AR hay una relación entre el tabaquismo y la aparición de manifestaciones pulmonares más graves (38). Entre el $38 \%$ al $73 \%$ de los pacientes con AR presentan compromiso pleural, principalmente derrame pleural, hallazgos que no están necesariamente relacionados con la enfermedad del parénquima pulmonar (27). El compromiso pleural puede desencadenar complicaciones como engrosamiento pleural que genere un efecto restrictivo pulmonar (38). Además, puede haber complicaciones mucho más raras, como un pseudoquilotórax, en el que el derrame pleural tiene gran cantidad de colesterol, aunque el mecanismo fisiopatológico de esta complicación no está claro (38).

Entre las afecciones de la vía aérea de la AR se describen la artritis cricoaritenoidea, paresia de las cuerdas vocales y bronquiectasias, estas últimas encontradas en un TACAR en el $30 \%$ de los pacientes, sin asociación con fibrosis pulmonar $(38,42)$. Dentro de las complicaciones relacionadas con la vía aérea en AR están la bronquiolitis obliterante - caracterizada por reducción en la luz bronquial por infiltración de células mononucleares-, la cual aparece en TACAR con un patrón en "mosaico de atenuación" con atrapamiento aéreo en imágenes obtenidas en espiración (1). Otra complicación es la bronquiolitis folicular, también llamada hiperplasia pulmonar linfoide, que se encuentra dentro del espectro de neumonía intersticial linfoide (LIP) con áreas de "árbol en gemación" y ocasionalmente bronquiectasias asociadas (38) (figura 8). El compromiso de la LIP se puede evidenciar en la radiografía de tórax como opacidades nodulares o reticulonodulares; sin embrago, en algunos casos la radiografía es normal (38). En un TACAR se evidencian nódulos centrolobulillares con medidas de 1 a $12 \mathrm{~mm}$ de diámetro y con halo en "vidrio esmerilado", además, en el parénquima se encuentran parches de opacidades en "vidrio esmerilado", bronquiectasias y "árbol en gemación" (38).

Por otro lado, en el $20 \%$ de pacientes con diagnóstico de AR se encuentran nódulos pulmonares reumatoideos (43) (figura 8). Dichos nódulos están relacionados con la aparición de nódulos subcutáneos y son evidentes durante los estadios avanzados de la enfermedad; sin embargo, su presencia no refleja la actividad de la enfermedad (38). En TCMD se observan nódulos sólidos con bordes bien definidos, no mayores a $5 \mathrm{~cm}$, ubicados en la periferia y cavitados en un $50 \%$ de los casos (38). Si los nódulos tienen calcificaciones, podrían indicar síndrome de Caplan, que se relaciona con enfermedad ocupacional — como la silicosis, que es la más frecuente (1) - .

La afectación intersticial ocurre en un 20 a $30 \%$ de los pacientes, principalmente con patrones de NIU, NINE y NO, con predominio de NIU, y se acompaña de otros hallazgos concomitantes, como el compromiso pleural, que sugiere un diagnóstico de AR (38).

Otros efectos secundarios se derivan del tratamiento de AR. Puede haber toxicidad pulmonar por el uso de metotrexato en un 5\% a $10 \%$ de los casos; sin embargo, no se ha encontrado relación entre dosis o tiempo de duración específicos para presentar la toxicidad pulmonar $(43,44)$. Por otro lado, el uso de antagonistas del factor de necrosis tumoral (TNF), como el infliximab, puede relacionarse con la aparición de infecciones granulomatosas aproximadamente en 239 de cada 100.000 pacientes; de estas, la más frecuente es la infección por Mycobacterium tuberculosis, por lo que la Sociedad Británica de Tórax (SBT), recomienda la toma de una radiografía de tórax antes de iniciar esta terapia $(45,46)$. 


\section{Etiología hereditaria}

\subsection{Neurofibromatosis tipo 1}

La neurofibromatosis tipo 1 (NF-1), también llamada enfermedad de Von Recklinghausen, es un síndrome neurocutáneo con patrón de herencia autosómico dominante causado por la mutación del gen NF1, localizado en el cromosoma 17 (9). Sin embargo, hasta en el $50 \%$ de los casos puede ocurrir por una mutación espontánea (47). La NF1 es la enfermedad más común del grupo de las facomatosis, y se presenta en 1 de cada 2.000 nacidos vivos (47). Dentro de los órganos más frecuentemente afectados están la piel, el sistema nervioso central, los huesos y las glándulas endocrinas (47).

El compromiso cutáneo se caracteriza por las manchas "café con leche", neurofibromas y hamartomas en iris denominados "nódulos de Lisch" (9). Dichos neurofibromas se producen a partir de las células Schwann y fibroblastos en cualquier nervio periférico, con mayor frecuencia en el V par craneal, y usualmente en el $30 \%$ de los pacientes se encuentra como única presentación clínica (48). Sin embargo, la manifestación clínica típica de la NF1 consiste en áreas circunscritas de piel con incremento de las manchas "cafés con leche" y tumores cutáneos o subcutáneos (49). También puede haber otros hallazgos, como pecas axilares, nódulos de Lisch, displasias óseas y múltiples tumores en el SNC (gliomas en nervios ópticos) $(48,49)$.

En el tórax, la NF1 tiende a aparecer más en los tejidos blandos, debido a la distribución de nervios periféricos en su superficie (9). Los principales hallazgos son: neurofibromas subcutáneos bien definidos, escoliosis torácica, alteración en la morfología de los cuerpos vertebrales, compromiso mediastinal por tumores neurogénicos (neurofibromas y schwannomas) (figura 9) y las anormalidades en la configuración de las costillas debido a displasias óseas o erosión por los neurofibromas adyacentes (47). Los neurofibromas subcutáneos son nódulos con densidad de tejidos blandos, usualmente son múltiples y bien definidos, no tienen importante realce con el medio de contraste. En el diagnóstico diferencial se deben incluir neoplasias cutáneas primarias y secundarias, quistes sebáceos o quistes epidérmicos (vistos, por ejemplo, en el síndrome de Gardner) (47).

Ahora bien, dentro de lo poco común que es el compromiso del pulmón por la NF1, se pueden encontrar áreas de apariencia quística o bullas, de predominio en lóbulos superiores y de ubicación subpleural simulando un enfisema paraseptal (9). Además, en las bases pulmonares puede encontrarse compromiso por anormalidades pulmonares intersticiales, con bandas subpleurales y reticulación sugestivas de fibrosis pulmonar (9).

\subsection{Esclerosis tuberosa}

La esclerosis tuberosa es una enfermedad autosómica dominante relacionada con la mutación del gen supresor de tumores TSC1 en el cromosoma 9 y TSC2 en el cromosoma 16 (50). Estas mutaciones predisponen a la generación de lesiones benignas, circunscritas y no invasivas, que pueden originarse en cualquier órgano (50). Esta entidad se presenta en 1 de cada 6.000 nacidos vivos, aproximadamente (51). Se han descrito diagnósticos prenatales mediante ultrasonido y RM, con la identificación de lesiones cardiacas y cerebrales (50).

El $90 \%$ de los pacientes llega a tener manifestaciones en la piel $(9,50)$. Otros órganos frecuentemente afectados son: el cerebro, en un $90 \%$; los riñones, en un $70 \%$ a $90 \%$ y la retina, en un $40 \%$ a $50 \%$ de los pacientes (50). Entre las manifestaciones cutáneas se encuentran los adenomas sebáceos y los fibromas periungueales, también llamados tumores de Koenen, en el $25 \%$ de los pacientes con esclerosis tuberosa $(9,50)$. Otras manifestaciones descritas, pero menos específicas, son los parches de Fitzpatrick, las lesiones hipomelanóticas y las lesiones en piel de naranja en el dorso que usualmente representan hamartomas $(9,50)$.

La linfangioleiomiomatosis (LAM) hace parte del espectro de compromiso torácico en pacientes con esclerosis tuberosa, que afecta mujeres premenopáusicas, y muy ocasionalmente a los hombres (50). La LAM puede ser esporádica o relacionada con esclerosis tuberosa, esta última con una frecuencia estimada en $1 \%$ a $3 \%$ de los pacientes con esclerosis tuberosa $(50,52)$. La LAM se caracteriza por un reemplazo del parénquima pulmonar por lesiones quísticas, debido a una proliferación de celulas similares a las del músculo liso alveolar, pero con receptores de progesterona, estrógenos y proteínas relacionadas con melanina (53). En la radiografía de tórax se puede encontrar aumento de los volúmenes pulmonares con aplanamiento diafragmático, aumento del espacio retroesternal y opacidades reticulares, aunque cabe resaltar que hasta en el $26 \%$ de pacientes la radiografía de tórax se considera normal (54). En la TACAR aparecen quistes difusos con paredes delgadas, usualmente no mayores de 20 mm y nódulos pulmonares asociados (figura 10). Si los nódulos son de mayor tamaño, se puede pensar en angiomiolipomas pulmonares como diagnóstico diferencial (9).

\section{Etiología adquirida}

\subsection{Sarcoma de Kaposi}

El sarcoma de Kaposi consiste en lesiones mesenquimales multisistémicas que involucran los vasos sanguíneos y los vasos linfáticos (9). Su etiología está relacionada con la infección latente por el herpes virus 8 , el cual es un proceso reactivo y no un proceso neoplásico como se consideraba antes (9). Esta entidad está claramente asociada al sida, con un conteo de CD4 menor a 100 células por mililitro; sin embargo, la prevalencia de la enfermedad ha disminuido considerablemente gracias a la terapia antirretroviral oportuna (55).

Uno de los órganos más afectados es la piel; sin embargo, también puede afectar el tracto gastrointestinal, ganglios linfáticos y el pulmón (9). El compromiso dermatológico es importante, ya que este puede preceder el compromiso sistémico (56). Las lesiones cutáneas pequeñas de color rosado $y$, posteriormente, violáceas son el principal hallazgo cutáneo (9).

El compromiso pulmonar ocurre en que un $45 \%$ de los casos, $15 \%$ de ellos sin efecto cutáneo asociado (56). La afectación torácica puede involucrar el pulmón, la tráquea, la pleura o la pared torácica $(9,56)$. El estudio inicial con radiografía de tórax puede evidenciar la enfermedad primaria o infecciones por gérmenes oportunistas (56). Cuando la radiografía de tórax muestra opacidades reticulares, asociadas a nódulos pulmonares y engrosamiento del intersticio peribroncovascular que predomina en el lóbulo medio y lóbulos inferiores, sugiere enfermedad primaria por sarcoma de Kaposi (56). En algunos casos la radiografía de tórax puede ser normal $(9,57)$. La TACAR muestra nódulos mal definidos, bilaterales, con 
distribución peribroncovascular, usualmente, con un diámetro mayor a $1 \mathrm{~cm}$, en algunos casos con signo del "halo" (56) (figura 11). Se pueden encontrar adenomegalias mediastinales hasta en el $50 \%$ de pacientes (9). Por otro lado, masas cutáneas y subcutáneas o lesiones líticas del esternón o en la columna torácica son las características del compromiso de la pared torácica $(56,58)$.

Los hallazgos radiológicos relevantes en cada una de las entidades mencionadas se resumen en la tabla 1 .

\section{Tabla 1. Resumen de hallazgos radiológicos de enfermedades sistémicas con compromiso torácico y dermatológico}

\begin{tabular}{|c|c|c|}
\hline Entidad & $\begin{array}{l}\text { Hallazgos } \\
\text { radiológicos } \\
\text { principales }\end{array}$ & $\begin{array}{l}\text { Hallazgos } \\
\text { radiológicos } \\
\text { complementarios }\end{array}$ \\
\hline $\begin{array}{l}\text { Embolismo } \\
\text { séptico }\end{array}$ & $\begin{array}{l}\text { Nódulos pulmonares } \\
\text { de márgenes mal } \\
\text { definidos, cavitados. }\end{array}$ & $\begin{array}{l}\text { Derrame pleural, } \\
\text { empiema. }\end{array}$ \\
\hline $\begin{array}{l}\text { Síndrome de } \\
\text { SAPHO }\end{array}$ & $\begin{array}{l}\text { Hiperostosis en la } \\
\text { pared anterior del } \\
\text { tórax, especialmente } \\
\text { en la unión } \\
\text { esternoclavicular y } \\
\text { esternocostal. }\end{array}$ & $\begin{array}{l}\text { "Bull head sign" } \\
\text { en la región } \\
\text { esternoclavicular en la } \\
\text { gammagrafía ósea. }\end{array}$ \\
\hline Sarcoidosis & $\begin{array}{l}\text { Adenomegalias } \\
\text { mediastinales y } \\
\text { parahiliares y nódulos } \\
\text { de distribución } \\
\text { perilinfática y } \\
\text { subpleural. }\end{array}$ & $\begin{array}{l}\text { Placas pleurales, } \\
\text { derrame pleural, } \\
\text { estenosis traqueal } \\
\text { o engrosamiento } \\
\text { nodular de paredes } \\
\text { bronquiales. }\end{array}$ \\
\hline $\begin{array}{l}\text { Polimiositis/ } \\
\text { dermatomiositis }\end{array}$ & $\begin{array}{l}\text { Enfermedad } \\
\text { intersticial (78 \%): } \\
\text { predominantemente } \\
\text { NO (44 \%), NIU (37\%) } \\
\text { y NINE (13,7 \%). }\end{array}$ & $\begin{array}{l}\text { Neumonía por } \\
\text { aspiración, } \\
\text { adelgazamiento de } \\
\text { músculos intercostales. }\end{array}$ \\
\hline $\begin{array}{l}\text { Esclerosis } \\
\text { sistémica }\end{array}$ & $\begin{array}{l}\text { Enfermedad } \\
\text { intersticial (70-90 \%): } \\
\text { NINE (70 \%), NIU } \\
(26 \%)\end{array}$ & $\begin{array}{l}\text { Hipertensión pulmonar } \\
\text { arterial, dilatación } \\
\text { esofágica. }\end{array}$ \\
\hline $\begin{array}{l}\text { Síndrome de } \\
\text { Sjögren }\end{array}$ & $\begin{array}{l}\text { Enfermedad } \\
\text { intersticial (25\%): } \\
\text { NINE (45\%), NIU } \\
(13 \%), \text { NO (10 \%), NIL } \\
\text { (3\%). }\end{array}$ & $\begin{array}{l}\text { Engrosamiento de } \\
\text { paredes bronquiales, } \\
\text { bronquiectasias, } \\
\text { bronquioloectasias. }\end{array}$ \\
\hline $\begin{array}{l}\text { Lupus eritematoso } \\
\text { sistémico }\end{array}$ & $\begin{array}{l}\text { Derrame pleural } \\
\text { bilateral y } \\
\text { engrosamiento pleural, } \\
\text { derrame pericárdico, } \\
\text { tromboembolismo } \\
\text { pulmonar. }\end{array}$ & $\begin{array}{l}\text { Neumonía bacteriana } \\
\text { por gérmenes } \\
\text { comunes, hemorragia } \\
\text { alveolar. }\end{array}$ \\
\hline $\begin{array}{l}\text { Artritis } \\
\text { reumatoide }\end{array}$ & $\begin{array}{l}\text { Enfermedad } \\
\text { intersticial (5-58 \%): } \\
\text { NIU (41\%), NINE } \\
\text { (30\%) y NO (8\%). }\end{array}$ & $\begin{array}{l}\text { Nódulos pulmonares } \\
\text { reumatoides, } \\
\text { neumonitis por } \\
\text { medicamentos, } \\
\text { derrame pleural. }\end{array}$ \\
\hline $\begin{array}{l}\text { Neurofibromatosis } \\
\text { tipo } 1\end{array}$ & $\begin{array}{l}\text { Tumores neurogénicos } \\
\text { (neurofibromas y } \\
\text { schwannomas), } \\
\text { neurofibromas } \\
\text { subcutáneos. }\end{array}$ & $\begin{array}{l}\text { Áreas de apariencia } \\
\text { quística o bullas de } \\
\text { predominio en lóbulos } \\
\text { superiores. }\end{array}$ \\
\hline $\begin{array}{l}\text { Sarcoma de } \\
\text { Kaposi }\end{array}$ & $\begin{array}{l}\text { Nódulos pulmonares } \\
\text { de distribución } \\
\text { peribroncovascular } \\
\text { con signo del "halo". }\end{array}$ & $\begin{array}{l}\text { Adenomegalias } \\
\text { mediastinales. }\end{array}$ \\
\hline
\end{tabular}


24. Mainetti C, Terziroli Beretta-Piccoli B, Selmi C. Cutaneous manifestations of dermatomyositis: A comprehensive review. Clin Rev. 2017;53(3):337-56. doi: 10.1007/ s12016-017-8652-1

25. Hallowell R, Ascherman D, Danoff S. Pulmonary manifestations of polymyositis/ dermatomyositis. Sem Respir Crit Care Med. 2014;35(2):239-48. doi: 10.1055/s0034-1371528.

26. Owens GR, Follansbee WP. Cardiopulmonary manifestations of systemic sclerosis. Chest. 1987;91(1):118-27. doi: 10.1378/chest.91.1.118

27. Copobianco J, Grimberg A, Thompson BM, Antunes VB, Jasinowodolinski D, Meirelles GS. Thoracic manifestations of collagen vascular diseases. Radiographics 2012;32:33-50. doi: 10.1148/rg.321105058

28. Denton CP, Khanna D. Systemic sclerosis. The Lancet. 2017;390(10103):1685-99. doi: 10.1016/S0140-6736(17)30933-9.

29. Hamaguchi Y. Autoantibody profiles in systemic sclerosis: predictive value for clinical evaluation and prognosis. J Dermatol. 2010;37(1):42-53. doi: 10.1111/j.13468138.2009.00762.x

30. Stojan G, Baer AN, Danoff SK. Pulmonary manifestations of Sjögren's syndrome. Curr Allergy Asthma Rep. 2013;13(4):354-60. doi:10.1007/s11882-013-0357-9

31. Obermoser G, Sontheimer RD, Zelger B. Overview of common, rare and atypical manifestations of cutaneous lupus erythematosus and histopathological correlates. Lupus. 2010;19(9):1050-70. doi: 10.1177/0961203310370048

32. Goh YP, Naidoo P, Ngian GS. Imaging of systemic lupus erythematosus. Part I: CNS, cardiovascular, and thoracic manifestations. Clin Radiol. 2013;68(2):181-91. doi:10.1016/j.crad.2012.06.110

33. Kinder BW, Freemer MM, King TE Jr, Lum RF, Nitiham J, Taylor K, et al. Clinical and genetic risk factors for pneumonia in systemic lupus erythematosus. Arthritis Rheum. 2007;56(8):2679-86. doi: 10.1002/art.22804

34. Paran D, Fireman E, Elkayam O. Pulmonary disease in systemic lupus erythematosus and the antiphospholipid syndrome. Autoimmun Rev. 2004;3(1):70-5. doi: 10.1016/ S1568-9972(03)00090-9.

35. Wahl DG, Guillemin F, de Maistre E, Perret C, Lecompte T, Thibaut G. Risk for venous thrombosis related to antiphospholipid antibodies in systemic lupus erythematosus a meta analysis. Lupus. 1997;6(5):467-73. doi: 10.1177/096120339700600510.

36. Hoffbrand BI, Beck ER. "Unexplained" dyspnoea and shrinking lungs in systemic lupus erythematosus. BMJ. 1965;1(5445):1273-7. doi: 10.1136/bmj.1.5445.1273

37. Warrington KJ, Moder KG, Brutinel WM. The shrinking lungs syndrome in systemic lupus erythematosus. Mayo Clin Proc. 2000;75(5):467-72. doi: https://doi. org/10.4065/75.5.467

38. Massey H, Darby M, Edey A. Thoracic complications of rheumatoid disease. Clin Radiol. 2013;68(3):293-301. doi:10.1016/j.crad.2012.07.007.

39. Turesson C, Fallon WM, Crowson CS, Gabriel SE, Matteson EL. Extraarticular disease manifestations in rheumatoid arthritis: incidence trends and risk factors over 46 years. Ann Rheum Dis. 2003:62(8):722-7. doi: 10.1136/ard.62.8.722

40. Prete M, Racanelli V, Digiglio L, Vacca A, Dammacco F, Perosa F. Extra-articular manifestations of rheumatoid arthritis: An update. Autoimmunity Reviews. 2011;11(2):12331. doi:10.1016/j.autrev.2011.09.001

41. Lora V, Cerroni L, Cota C. Skin manifestations of rheumatoid arthritis. G Ital Dermatol Venereol. 2018;153(2):243-55. doi: 10.23736/S0392-0488.18.05872-8

42. Lieberman-Maran L, Orzano IM, Passero MA, Lally EV. Bronchiectasis in rheumatoid arthritis: Report of four cases and a review of the literature implications for management with biologic response modifiers. Sem Arthr Rheumat. 2006;35(6):379-87. doi:10.1016/j.semarthrit.

43. Franquet, T. High-resolution CT of lung disease related to collagen vascular disease. Radiol Clin North America. 2001;39(6):1171-87. doi:10.1016/s0033-8389(05)70337-

44. Rossi SE, Erasmus JJ, McAdams HP, Sporn TA, Goodman PC. Pulmonary drug toxicity: Radiologic and pathologic manifestations. RadioGraphics. 2000;20(5):1245-59. doi:10.1148/radiographics.20.5.g00se081245

45. Wallis RS, Broder MS, Wong JY, Hanson ME, Beenhouwer DO. Granulomatous infectious diseases associated with tumor necrosis factor antagonists. Clin Infect Dis. 2004;38(9):1261-5. doi:10.1086/383317

46. British Thoracic Society Standards of Care Committee. BTS recommendations for assessing risk and for managing Mycobacterium tuberculosis infection and disease in patients due to start anti-TNF- treatment, Thorax. 2005;60(10):800-5. doi:10.1136/ thx.2005.046797

47. Fortman BJ, Kuszyk BS, Urban BA, Fishman EK. Neurofibromatosis Type 1: A diagnostic mimicker at CT. RadioGraphics. 2001;21(3):601-12. doi:10.1148/ radiographics.21.3.g01ma05601

48. Boley S, Sloan JL, Pemov A, Stewart DR. A quantitative assessment of the burden and distribution of lisch nodules in adults with neurofibromatosis type 1. Investigative Opthalmology \& Visual Science. 2009;50(11):5035. doi:10.1167/iovs.09-3650

49. Williams M, Verity CM. Optic nerve gliomas in children with neurofibromatosis. Lancet. 1987;1:1318-9.

50. Curatolo P, Bombardieri R, Jozwiak S. Tuberous sclerosis. The Lancet. 2008;372(9639):657-68. doi:10.1016/s0140-6736(08)61279-9

51. Osborne JP, Fryer A, Webb D. Epidemiology of tuberous sclerosis. Ann N Y Academy Sciences. 1991;615:125-7. doi: https://doi.org/10.1111/j.1749-6632.1991.tb37754.x

52. Hancock E, Osborne J. Lymphangioleiomyomatosis: a review of the literature. Respir. Med. 2002;96:1-6. doi: 10.1053/rmed.2001.1207.
53. Ferrans VJ, Yu ZX, Nelson WK, et al. Lymphangioleiomyomatosis (LAM): a review of clinical and morphological features. J Nippon Med Sch. 2000;67(5):311-29. doi: $10.1272 /$ jnms.67.311

54. Chu SC, Horiba K, Usuki J, Avila NA, Chen CC, Travis WD, et al. Comprehensive evaluation of 35 patients with lymphangioleiomyomatosis. Chest. 1999;115(4):104152. doi:10.1378/chest.115.4.1041

55. Bower M, Palmieri C, Dhillon T. AIDS-related malignancies: changing epidemiology and the impact of highly active antiretroviral therapy. Curr Opin Infect Dis. 2006;19(1):14-9. doi: 10.1097/01.qco.0000200295.30285.13.

56. Restrepo CS, Martínez S, Lemos JA, Carrillo JA, Lemos DF, Ojeda P, Koshy P. Imaging manifestations of Kaposi sarcoma. Radiographics. 2006;26(4):1169-85. doi: 10.1148 rg.264055129.

57. Willatt HJ, Moyano NC, Apey RC, Lidid AL. Sarcoma de Kaposi extratorácico: evidencias de una enfermedad multisistémica. Rev. chil. radiol. 2010;16(2):80-5. http:// dx.doi.org/10.4067/S0717-93082010000200008

58. Wolff SD, Kuhlman JE, Fishman EK. Thoracic Kaposi sarcoma in AIDS: CT findings J Comput Assist Tomogr. 1993;17(1):60-2. doi: 10.1097/00004728-199301000-00010.

\section{Correspondencia}

Felipe Aluja-Jaramillo

Hospital Universitario San Ignacio

Departamento de Radiología

Carrera 7 \# 40-62

falujaj@husi.org.co

Recibido para evaluación: 19 de agosto de 2020

Aceptado para publicación: 14 de diciembre de 2020 